\title{
Host PDZ-containing proteins targeted by SARS-CoV-2
}

\author{
Célia Caillet-Saguy ${ }^{1}$ (D), Fabien Durbesson ${ }^{2}$, Veronica V. Rezelj ${ }^{3}$, Gergö Gogl ${ }^{4}$, Quang Dinh \\ $\operatorname{Tran}^{3,5}$ (iD), Jean-Claude Twizere ${ }^{6}$, Marco Vignuzzi ${ }^{3}$, Renaud Vincentelli ${ }^{2}$ and Nicolas Wolff ${ }^{1}$ \\ 1 Institut Pasteur, Unité Récepteurs-Canaux, UMR CNRS 3571, Paris, France \\ 2 AFMB, UMR CNRS 7257, Marseille, France \\ 3 Institut Pasteur, Unité Populations Virales et Pathogénèse, UMR CNRS 3569, Paris, France \\ 4 IGBMC, INSERM U1258/UMR CNRS 7104, Illkirch, France \\ 5 École doctorale BioSPC, Université Paris Diderot, Sorbonne Paris Cité, France \\ 6 GIGA Institute, Molecular Biology of Diseases, Viral Interactomes laboratory, University of Liege, Belgium
}

\section{Keywords}

$3 \mathrm{~A}$ and $\mathrm{N}$; human PDZ library; PDZ-binding motif; PDZ-containing protein; SARS-CoV-2; viral proteins $\mathrm{E}$; viral replication

\section{Correspondence \\ C. Caillet-Saguy, N. Wolff, Institut Pasteur, Unité Récepteurs-Canaux, UMR CNRS 3571, 75015 Paris, France \\ Tel: +0033145688872 \\ E-mails: celia.caillet-saguy@pasteur.fr and nicolas.wolff@pasteur.fr}

Renaud Vincentelli and Nicolas Wolff contributed equally as last authors.

(Received 2 February 2021, revised 31 March 2021, accepted 13 April 2021)

doi:10.1111/febs.15881
Small linear motifs targeting protein interacting domains called PSD-95/ Dlg/ZO-1 (PDZ) have been identified at the $\mathrm{C}$ terminus of the severe acute respiratory syndrome coronavirus 2 (SARS-CoV-2) proteins $\mathrm{E}, 3 \mathrm{a}$, and $\mathrm{N}$. Using a high-throughput approach of affinity-profiling against the full human PDZome, we identified sixteen human PDZ binders of SARS-CoV2 proteins $\mathrm{E}, 3 \mathrm{~A}$, and $\mathrm{N}$ showing significant interactions with dissociation constants values ranging from 3 to $82 \mu \mathrm{M}$. Six of them (TJP1, PTPN13, HTRA1, PARD3, MLLT4, LNX2) are also recognized by SARS-CoV while three (NHERF1, MAST2, RADIL) are specific to SARS-CoV-2 E protein. Most of these SARS-CoV-2 protein partners are involved in cellular junctions/polarity and could be also linked to evasion mechanisms of the immune responses during viral infection. Among the binders of the SARS-CoV-2 proteins $\mathrm{E}, 3 \mathrm{a}$, or $\mathrm{N}$, seven significantly affect viral replication under knock down gene expression in infected cells. This PDZ profiling identifying human proteins potentially targeted by SARS-CoV-2 can help to understand the multifactorial severity of COVID19 and to conceive effective anti-coronaviral agents for therapeutic purposes.

\section{Introduction}

Coronaviruses $(\mathrm{CoV})$ are enveloped viruses that primarily infect birds and mammals. Some CoVs have evolved to establish zoonotic disease in humans, potentially causing severe respiratory illnesses [1]. The seriousness of $\mathrm{CoV}$ infection during the last outbreaks caused by the severe acute respiratory syndrome coronavirus 1 (SARS-CoV) in 2003, the Middle East Respiratory Syndrome-virus (MERS-CoV) in 2012 and the SARS-CoV-2 in 2020 [2], and the lack of effective treatment for $\mathrm{CoV}$ infection highlight the need of a deeper understanding of coronavirus molecular biology to elaborate therapeutic strategies that counteract SARS-CoV-2 infection. However, limited knowledge of the molecular details of SARS-CoV-2 infection precludes a fast development of compounds targeting the host-virus interface. Several SARS-CoV-2 interactomes have been recently published using mass spectrometry [3-5]. Unfortunately, some transient and weak interactions with affinities in the $1-100 \mu \mathrm{m}$ range can be hardly detected by such approaches. However, during

\footnotetext{
Abbreviations

Bls, binding intensities; CoV, coronaviruses; DV, Dengue virus; E, envelope; HPV, human papillomavirus; $K_{d}$, dissociation constant; M, membrane; MERS-CoV, Middle East Respiratory Syndrome virus; N, nucleocapsid; PBMs, PDZ-Binding Motifs; PDZ, PSD-95/Dlg/ZO-1; PDZome, PDZ domains identified in the human genome; PFU, plaque forming units; S, spike; SARS-CoV, severe acute respiratory syndrome coronavirus 1; SARS-CoV-2, severe acute respiratory syndrome coronavirus 2; SLiMs, short linear motifs; TCR, T-cell receptor; TM, transmembrane; WNV, West Nile Virus.
} 
infection, viruses target host signaling pathways that mainly involve protein-protein interactions of low affinity, as transient bindings are essential for the dynamics of cellular homeostasis.

Hijacking of cellular protein functions is a widely used strategy for viruses as they are obligate intracellular pathogens. Each step of the viral life cycle from entry to transmission is orchestrated through interactions with cellular proteins. All families of viruses manipulate the cell proteome by targeting key proteins involved in the control of cell defense and homeostasis. Interactions mediated by short linear motifs (SLiMs) are ubiquitous in the eukaryotic proteome [6], and the adaptation of viruses to their environment involves the extensive use of SLiM mimicry to subvert host functionality [7].

PSD-95/Dlg/ZO-1 (PDZ)-binding motifs (PBMs) are SLiMs that interact with a large family of protein interaction domains called PDZ. PBMs are usually located at the extreme carboxyl terminus of proteins [8]. The PDZ-PBM interactome is one of the most prominent instances of a SLiM-mediated protein interaction network serving key cell signaling purposes [9]. PBMs were identified in diverse proteins of many viruses responsible for acute to chronic infections [10,11]. Cellular PDZ-viral PBM interactions were shown to be directly involved in viral pathogenicity of SARS-CoV, as well as of rabies virus and in the oncogenicity of human papillomavirus (HPV) [10]. During infection, the viral proteins compete with the endogenous ligands through the binding to the PDZ domain of the host protein targets allowing a cellular relocalization, sequestration, or degradation of protein [12] but can also affect the catalytic activity of signaling proteins [13]. Functional perturbations of cellular processes due to interactions between viral PBMs and cellular PDZ-containing proteins can facilitate the virus life cycle in the host and the dissemination to new hosts. Thus, targeting the PBM-PDZ interface could potentially lead to novel antiviral therapies.

The four major structural proteins encoded by the coronavirus genome, the spike (S) protein, the nucleocapsid $(\mathrm{N})$ protein, the membrane $(\mathrm{M})$ protein, and the envelope (E) protein, participate in different aspects of the replication cycle and ultimately form a structurally complete viral particle. While a minor fraction is incorporated into the virion envelope, the integral membrane $\mathrm{E}$ protein $(\sim 8-12 \mathrm{kDa})$ of $\mathrm{CoVs}$ including SARS-CoVs is a multifunctional protein that forms ion channels with its transmembrane (TM) domain. This channel activity is mediated by formation of pentameric oligomers and is only mildly selective for cations [14]. The channel would be active in the secretory pathway, altering luminal environments, rearranging secretory organelles, and leading to efficient trafficking of virions [15]. In addition, E protein interacts with host proteins, related to its extramembrane domain particularly the C-terminal domain.

The C-terminal sequence in extra membrane position is predicted to be partially folded (helices and $\beta$ coil- $\beta$ motif) which could affect the global conformation of the pentameric $\mathrm{E}$ channel suggesting that the channel activity of $\mathrm{E}$ and its protein interactions most likely interplay $[14,16]$. In addition, the $\mathrm{E}$ protein encodes a putative PBM sequence at its extreme $\mathrm{C}$ terminus (Fig. 1A) that could also interfere through protein-protein interactions with the oligomeric organization of $\mathrm{E}$ protein and consequently its channel activity. The PBM sequence of $\mathrm{E}$ protein has been identified as a virulence factor for SARS-CoV virus, influencing replication level, virus dissemination, and pathogenicity of SARS-CoV in animal models [17]. To date, E protein of SARS-CoV has only been reported to interact with five host proteins: Bcl-xL, PALS1/ MPP5, syntenin, sodium/potassium ATPase al subunit, and stomatin [16]. The relevance of these interactions is not yet fully understood. Among these five partners of SARS-CoV, PDZ domains of the PALS1/MPP5 tight junction protein and of Syntenin interact with the C-terminal PBM of $\mathrm{E}$ protein. PBM-PDZ interactions strongly impact the structure of mammalian epithelial cells and could contribute to the abrupt deterioration of the lung epithelium observed in patients infected by SARS-CoV [18]. Therefore, to better understand the influence of host PDZs and viral PBM motifs in the pathogenicity of SARS-CoV-2, we performed a targeted screen to identify cellular PDZ domains capable of interacting with $\mathrm{PBM}$ motifs $\mathrm{CoV}$ proteins.

In this study, we used the holdup assay [19], a highthroughput and quantitative approach that offers a high sensitivity for low-to-medium (1-100 $\mu \mathrm{M})$ affinity, typically found for PDZ/PBM interactions. We established the list of PDZ-containing partners potentially targeted by SARS-CoV-2 E protein through its PBM. This work identified $10 \mathrm{PDZ}$-containing proteins and determined the affinities of their PDZ to SARS-CoV-2 E protein PBM. Most of them are involved in cellular junction dynamics (PARD3, TJP1/ZO-1, LNX2, MLLT4, NHERF1). To further understand the potential implication of the PDZ-PBM in pathogenicity, we have also determined the PDZ-containing proteins recognized by the $\mathrm{E}$ protein of SARS-CoV and MERS-CoV viruses, as well as the PDZ binders of the SARS-CoV-2 $3 \mathrm{a}$ and $\mathrm{N}$ proteins that also encode for a C-terminal PBM sequence. From this PDZ list, we have selected 20 PDZ-containing partners of SARS- 


\section{A} SARS-COV2 MYSFVSEETGTLIVNSVLLFLAFVVFLLVTLAILTALRLCAYCCNIVNVSLVKPSFYVYSRVKNLNSSR-VPDLLV SARS-COV MYSFVSEETGTLIVNSVLLFLAFVVFLLVTLAILTALRLCAYCCNIVNVSLVKPTVYVYSRVKNLNSSEGVPDLLV

$T M$

B

$\begin{array}{ll}\text { SARS-COV2 } & - \text { NLNSSRVPDLLV } \\ \text { SARS-COOH } & - \text { LNSSEGVPDLLV } \\ \text { MERS } & - \text { DSKPPLPPDEWV } \\ \text { COOH }\end{array}$

C

$\begin{array}{lrc}\text { position } & -2 & -1 \\ \text { Class I } & \mathrm{S} / \mathrm{T}-\mathrm{X}-\phi_{\mathrm{COOH}} \\ \text { Class II } & \phi-\mathrm{X}-\phi_{\mathrm{COOH}} \\ \text { Class III } & \mathrm{D} / \mathrm{E}-\mathrm{X}-\phi_{\mathrm{COOH}}\end{array}$

Fig. 1. E protein sequences. (A) Comparison of $E$ protein sequences of SARS-CoV-2 and SARS-CoV viruses. The SARS-CoV-2 genome is very similar to SARS-CoV. The last three residues that form the PBM sequence (in bold) are strictly conserved. Deletion and substitution of amino acid close to the PBMs are colored in red. The TM helix is underlined. (B) Sequences of peptides used as baits in the holdup assays. PBM residues are in bold. (C) The three classes of PBM. $X$ is any amino-acid (position -1), and $\phi$ is a hydrophobic amino-acid (position 0).

$\mathrm{CoV}-2$ to assess their influence on SARS-CoV-2 replication in infected cells and found that the expression of seven of them is relevant for the efficiency of viral replication.

\section{Results}

\section{SARS-CoV-2 E protein recognizes several cellular PDZ-containing proteins}

The E protein of SARS-CoV virus is known to contain a C-terminal motif, a - $\mathrm{LLV}_{\mathrm{COOH}}$ sequence corresponding to a PBM of class II (Fig. 1C). This motif is strictly conserved in SARS-CoV-2 E protein (Fig. 1A). To quantify the binding activity of the SARS-CoV-2 E PBM and its upstream sequence, we used an in vitro automated high-throughput chromatography assay called holdup $[19,20]$. A 12-mer peptide was synthetized encompassing the C-terminal PBM sequence of SARS-CoV-2 E protein linked to a biotinyl group (Fig. 1B). This peptide was used as bait to quantify the interaction between the SARS-CoV-2 E protein PBM peptide and the full human PDZ domain library expressed in Escherichia coli. The updated PDZ library called PDZome V.2 covers $98 \%$ of the human 'PDZome' (266 over $272 \mathrm{PDZ}$ domains identified in the human genome) [20,21]. Each PDZ of the library is defined by the protein name followed by the PDZ number in the protein. The holdup approach displays a high sensitivity of detection for low-to-medium affinity $\mathrm{PDZ} / \mathrm{PBM}$ pairs and provides an affinity-based ranking of the identified binders corresponding to a specificity profile [22]. The holdup assay allows to measure binding intensities (BIs) for a large number of PDZ domain-PBM motif pairs. The datasets are plotted as specificity profiles (Fig. 2A) representing all the individual BIs measured for each PDZ domain for a peptide encompassing the PBM motif and its upstream sequence.

The specificity profiles for SARS-CoV, SARS-CoV2, and MERS-CoV E PBM with the mean values of BI are reported in Fig. 2A with an affinity-based ranking. Steady-state holdup BIs can be converted to dissociation constants as described previously [23]. For this, we determined the dissociation constants of a few PBM-PDZ interactions using a competitive fluorescence polarization assay. The holdup assay detected several significant interactions for the three viruses. Using a stringent threshold previously defined for significant detectable binders in holdup assays at $\mathrm{BI}>0.2$ ( $100 \mu \mathrm{M}$ dissociation constant), $10 \mathrm{PDZ}$ binders of SARS-CoV-2 E protein showed interactions with affinities values ranging from $2.6 \mu \mathrm{M}$ (TJP1_2) to $82 \mu \mathrm{M}$ (MLLT4; Fig. 2, zoomed-in view, Table 1). Thus, the PBM sequence of SARS-CoV-2 E protein has the capacity to bind in vitro several PDZ domains in the $1-100 \mu \mathrm{M}$ affinity range typically found for PDZ/PBM interactions. As illustrated by the sharp profile of interaction of Fig. 2A, SARS-CoV-2 E PBM recognizes only $4 \%$ of $\mathrm{PDZ}$ domains from the human PDZ library reflecting the specificity of these interactions. 
A

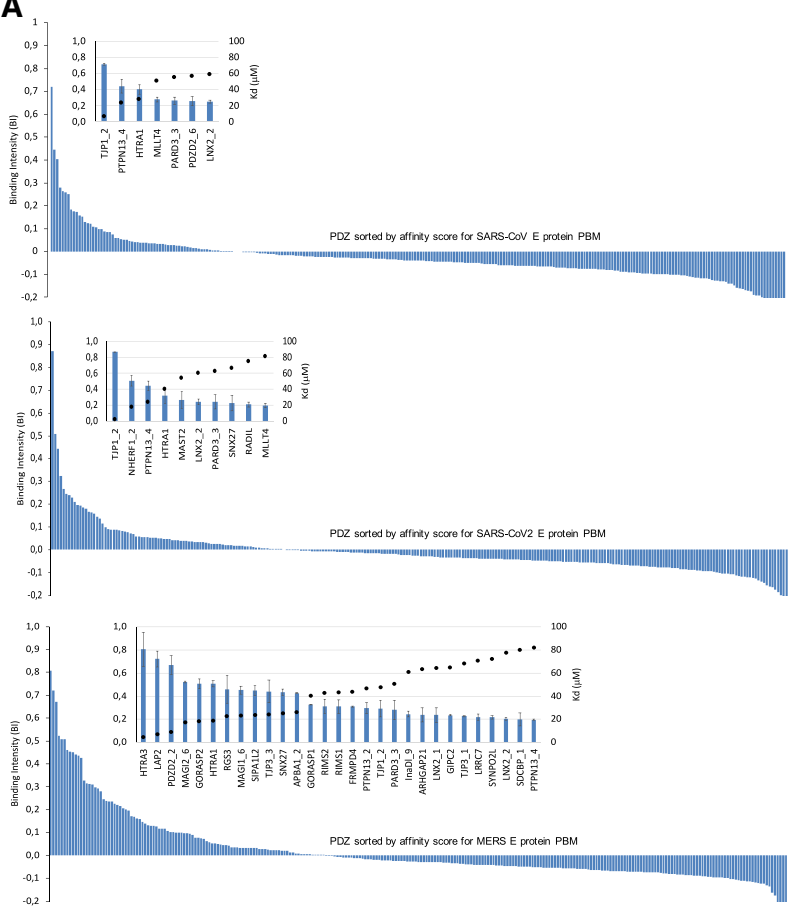

B

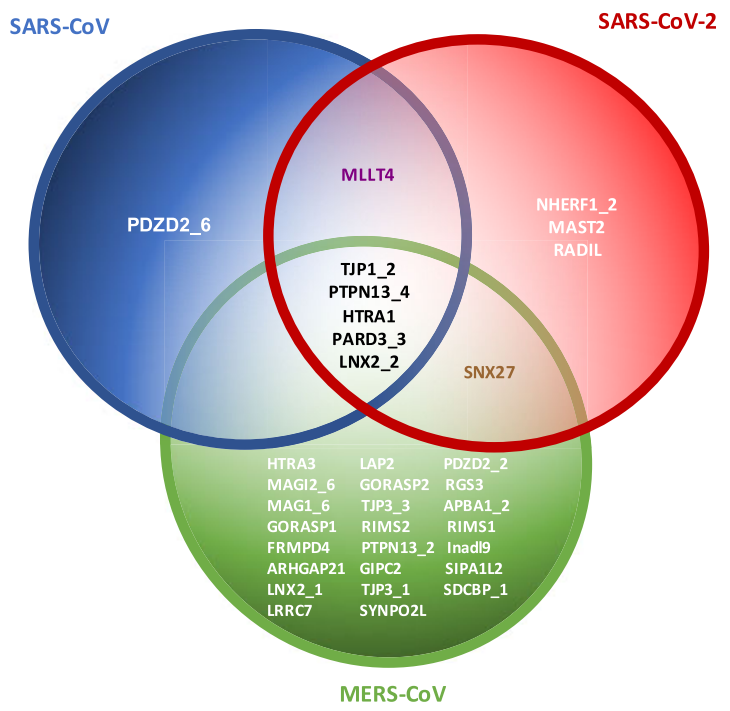

Fig. 2. PDZ binders of the E protein PBMs by holdup assay. (A) PDZome-binding profiles of the E protein PBMs by holdup assay of SARSCoV (upper panel), SARS-CoV-2 (middle panel) and MERS-CoV (bottom panel). PDZ domains are ranked by decreased BI values. Zoomed-in views show the 7, 10 and 29 PDZ binders of SARS-CoV, SARS-CoV-2 and MERS-CoV E proteins, respectively, which displayed significant $\mathrm{BI}$ values higher than 0.2. Error bars are standard deviations of two independent experiments. The black circles correspond to affinity values $\left(K_{d}\right)$ in $\mu \mathrm{M}$ (secondary $Y$ axis). (B) Venn diagram of PDZ binders of the $E$ protein PBMs of SARS-CoV, SARS-CoV-2 and MERS-CoV.

\section{Patterns of human PDZ-containing proteins preferentially targeted by E proteins expressed by SARS-CoV, SARS-CoV-2, and MERS-CoV viruses}

Two sequence differences between SARS-CoV and SARS-CoV-2 E proteins are observed upstream their identical PBM sequences (Fig. 1B).

Seven PDZ-containing proteins $(3 \%)$ were identified as binders of SARS-CoV E PBM by high-throughput holdup (Table 1). Six of them are also SARS-CoV-2 E PBM binders, ranked by decreased affinity values in Fig. 2B; TJP1-2, PTPN13_4, HTRA1, MLLT4, PARD3_3 LNX2_2. The affinities of SARS-CoV and SARS-CoV-2 E PBMs for this set of proteins are similar, in agreement with the strict conservation of the last five C-terminal positions of the PBM (p0 to $\mathrm{p}-4$ ) (Fig. 1A; Table 1). PDZ2_6 is only recognized by SARS-CoV E PBM while four additional PDZs are only recognized by SARS-CoV-2 E PBM (NHERF1_2, MAST2, RADIL, SNX27). Thus, the PBM upstream sequence differences increase the number of binders for SARS-CoV-2 protein E with four additional host partners.

The MERS-CoV E protein encodes for a class III PBM (Fig. 1B,C). As compared to the SARS-CoV/ SARS-CoV-2 E patterns, the profile of interaction of MERS-CoV E PBM is extended with a larger number of partners, that is, $29(11 \%)$, within the same range of affinities between 5 and $82 \mu \mathrm{m}$ (Table 1). Six out of seven PDZ-containing partners of SARS-CoV E PBM and six out of 10 PDZ-containing partners of SARSCoV-2 E PBM are also recognized by MERS-CoV E PBM (Fig. 2B).

\section{The C-terminal motifs of SARS-CoV-2 $\mathrm{N}$ and $3 \mathrm{a}$ proteins also bind to cellular PDZ-containing proteins}

Apart from the E protein, following a systematic search of the sequences of the 29 proteins found in SARS-CoV-2, the $3 \mathrm{a}$ protein and the nucleocapsid protein $\mathrm{N}$ were also found to contain PBMs. The 
Table 1. Measured $\mathrm{BI}$ and converted $K_{d}(\mu \mathrm{M})$ values of PDZ domains for the SARS-CoV (A), SARS-CoV-2 (B) and MERS-CoV (C) E protein PBMs. Only significant BI values higher than 0.2 are reported. When multiple holdup experiments were performed, the averaged $\mathrm{BI}$ values and standard deviations are reported.

\begin{tabular}{|c|c|c|c|c|c|c|c|c|c|c|c|}
\hline \multicolumn{4}{|c|}{ A } & \multicolumn{4}{|c|}{ B } & \multicolumn{4}{|c|}{ C } \\
\hline SARS-CoV E & $\mathrm{BI}$ & St & $K_{\mathrm{d}}$ & SARS-CoV-2 E & $\mathrm{BI}$ & St & $K_{\mathrm{d}}$ & MERS E & $\mathrm{BI}$ & St & $K_{\mathrm{d}}$ \\
\hline TJP1_2 & 0.72 & 0.01 & 7.0 & TJP1_2 & 0.87 & 0.00 & 2.6 & HTRA3 & 0.81 & 0.15 & 4.2 \\
\hline PTPN13_4 & 0.44 & 0.08 & 24 & NHERF1_2 & 0.51 & 0.07 & 18 & LAP2 & 0.72 & 0.07 & 6.9 \\
\hline HTRA1 & 0.40 & 0.06 & 28 & PTPN13_4 & 0.44 & 0.06 & 24 & PDZD2_2 & 0.67 & 0.08 & 8.9 \\
\hline MLLT4 & 0.28 & 0.03 & 51 & HTRA1 & 0.32 & 0.10 & 41 & MAGI2_6 & 0.52 & 0.01 & 17 \\
\hline PARD3_3 & 0.26 & 0.04 & 55 & MAST2 & 0.27 & 0.10 & 54 & GORASP2 & 0.51 & 0.04 & 18 \\
\hline PDZD2_6 & 0.26 & 0.06 & 57 & LNX2_2 & 0.25 & 0.04 & 61 & HTRA1 & 0.51 & 0.03 & 18 \\
\hline \multirow[t]{23}{*}{ LNX2_2 } & 0.25 & 0.02 & 59 & PARD3_3 & 0.24 & 0.09 & 63 & RGS3 & 0.46 & 0.12 & 22 \\
\hline & & & & SNX27 & 0.23 & 0.10 & 67 & MAGI1_6 & 0.45 & 0.03 & 23 \\
\hline & & & & RADIL & 0.21 & 0.03 & 75 & TJP3_3 & 0.44 & 0.10 & 24 \\
\hline & & & & MLLT4 & 0.20 & 0.02 & 82 & SNX27 & 0.44 & 0.03 & 25 \\
\hline & & & & & & & & APBA1_2 & 0.43 & 0.01 & 26 \\
\hline & & & & & & & & GORASP1 & 0.33 & 0.00 & 40 \\
\hline & & & & & & & & RIMS2 & 0.31 & 0.06 & 43 \\
\hline & & & & & & & & RIMS1 & 0.31 & 0.06 & 43 \\
\hline & & & & & & & & FRMPD4 & 0.31 & 0.00 & 43 \\
\hline & & & & & & & & PTPN13_2 & 0.30 & 0.04 & 46 \\
\hline & & & & & & & & TJP1_2 & 0.29 & 0.07 & 48 \\
\hline & & & & & & & & PARD3_3 & 0.28 & 0.08 & 50 \\
\hline & & & & & & & & InaDI_9 & 0.25 & 0.02 & 61 \\
\hline & & & & & & & & ARHGAP21 & 0.24 & 0.06 & 63 \\
\hline & & & & & & & & LNX2_1 & 0.24 & 0.06 & 64 \\
\hline & & & & & & & & GIPC2 & 0.24 & 0.01 & 65 \\
\hline & & & & & & & & TJP3_1 & 0.23 & 0.00 & 68 \\
\hline & & & & & & & & SIPA1L2 & 0.22 & 0.22 & 69 \\
\hline & & & & & & & & LRRC7 & 0.22 & 0.03 & 70 \\
\hline & & & & & & & & SYNPO2L & 0.22 & 0.01 & 72 \\
\hline & & & & & & & & LNX2_2 & 0.21 & 0.01 & 77 \\
\hline & & & & & & & & SDCBP_1 & 0.20 & 0.06 & 80 \\
\hline & & & & & & & & PTPN13_4 & 0.20 & 0,01 & 82 \\
\hline
\end{tabular}

PBM sequences of $\mathrm{E}$ and 3a proteins (Fig. 3A), two viroporins, belong to the same class of $\mathrm{PBM}$, the class II (Fig. 1C). While the PBM of the E protein is involved in SARS-CoV virulence and replication [17], the motif of the protein $3 \mathrm{a}$ has no significant impact on viral growth [24]. However, it has been shown that this accessory 3 a protein might exhibit compensatory function in the absence of $\mathrm{E}$, on viral replication in vitro and in vivo. This homology suggests that the $\mathrm{E}$ and 3 a proteins could interact with common host PDZ-containing proteins.

On the other hand, the potential PBM sequence at the $\mathrm{C}$ terminus of the structural nucleocapsid protein $\mathrm{N}$ is a class I motif with the atypical presence of a small hydrophobic residue, that is, an alanine, at the last position (Fig. 3A).

The binding profiles of PBM from SARS-CoV-2 3a and $\mathrm{N}$ proteins are reported in Fig. 3B. Five binders
(2\%) displayed significant BI values higher than 0.2 : TJP1_2, NHERF4_1, NHERF3_4, RGS3, and PARD3B_1, ranked by decreased affinity values. Interestingly, E proteins of SARS-CoV and SARS-CoV-2, and 3a protein of SARS-CoV-2 have the same best binder, TJP1_2, and both also recognized the PDZ domain of PARD3B. NHERF3 and NHERF4 are two new binders of SARS-CoV-2 while RGS3 is also recognized by MERS-CoV E protein. To note, the affinity range of 3 a protein for its binders is lower than the one of $\mathrm{E}$ protein, from 25 to $80 \mu \mathrm{M}$. As for the $\mathrm{N}$ protein PBM binders, only two PDZ domains $(1 \%)$ are identified: RHNP2 and GIPC1. These proteins have not been identified as binders of proteins $\mathrm{E}$ and $3 \mathrm{a}$. GIPC1 is a PDZ-containing protein recognized by the PBM of the hepatitis B virus capsid protein and can accommodate another atypical small $\mathrm{C}$-terminal residue, a cysteine [25]. 
A

$$
\begin{array}{ll}
\text { E PBM } & \text {-NLNSSRVPDLLV } \\
\text { 3a PBM } & \text {-YDEPTTTTSVPL } \\
\text { N PBM } & \text {-QQOHMSSADSTQA } \\
\text { COOH }
\end{array}
$$

$$
\text { B }
$$

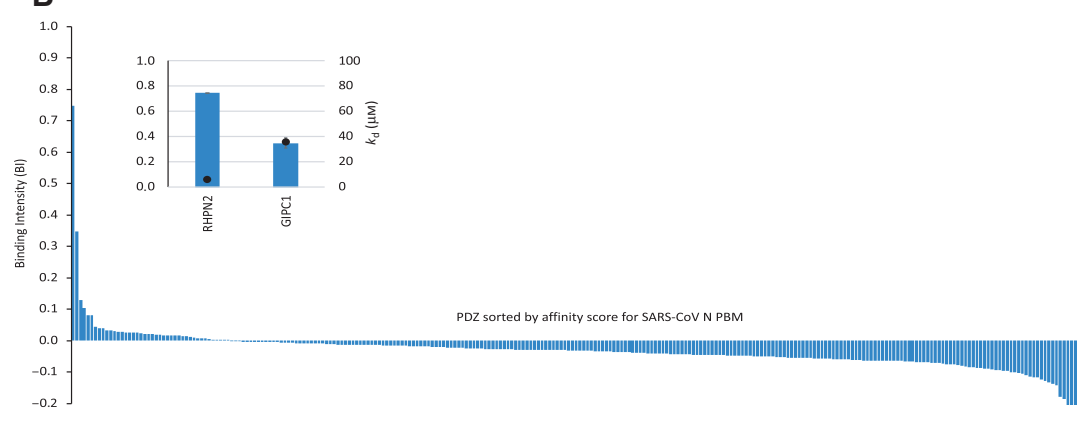

Fig. 3. PDZome-binding profiles of SARSCoV-2 N protein and 3a protein PBMs by holdup assay. (A) sequences of $E, N$ and $3 a$

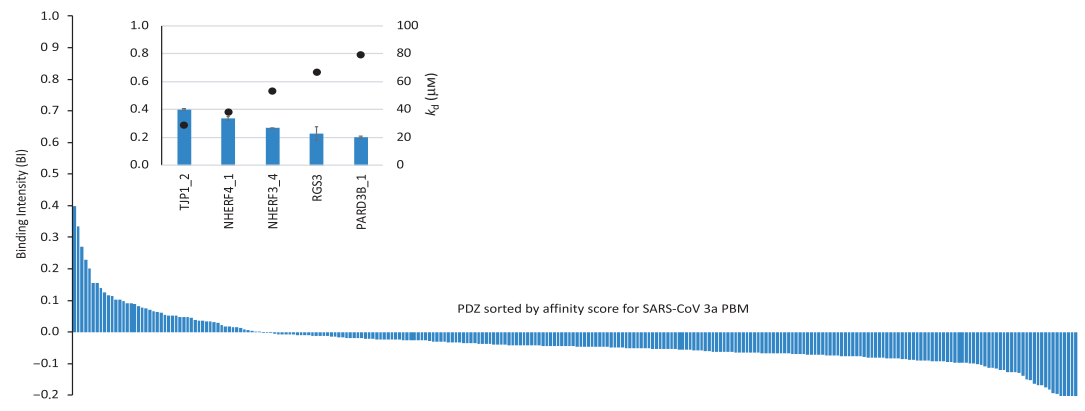
peptides used as baits in the holdup assays. (B) PDZ domains are ranked by decreased BI values. Zoomed-in views show the 2 and 5 PDZ binders of SARS-CoV-2 $\mathrm{N}$ and $3 a$ proteins, respectively, which displayed significant $\mathrm{BI}$ values higher than 0.2. The black circles correspond to affinity values $\left(K_{d}\right)$ in $\mu \mathrm{m}$ (secondary $Y$ axis). The data are representative of two independent experiments and error bars correspond to the standard deviation.

\section{Effects of depletion of cellular PDZ-containing proteins on SARS-CoV-2 replication}

We next investigated the biological role of the PDZcontaining partners of SARS-CoV-2 proteins in the viral replication according to our holdup assay results.

We established a list of potential PDZ partners recognized by at least one of the PBM motif encoded by the SARS-CoV-2 proteins E, 3a or N (Table 2). We selected the 16 PDZ partners identified with BIs higher than 0.2 (Figs $2 \mathrm{~B}$ and $3 \mathrm{~B}$ ) and added four additional PDZ partners with BI values comprised between 0.16 and 0.20; MPP5/PALS1, PDZD2, and DLG3 recognized by SARS-CoV-2 E protein and FRMPD4, a binder of both SARS-CoV-2 proteins E and 3A.

Twenty human PDZ-containing proteins were targeted for knockdown by siRNA transfection in human lung A549 cells. This cell line stably expresses the SARS-CoV-2 receptor ACE2 [26]. Our approach to knockdown gene expression used siRNA pools containing a mixture of four individual siRNAs, that are designed and modified for greater specificity, providing guaranteed gene silencing of human targets. We have validated these siRNA pools previously in a screen carried out in human A549 cells overexpressing ACE-
2. Our approach confirmed that knockdown of a number of different genes, including the receptor ACE-2, and other unexpected genes such as BZW2 or BRD4 reduces SARS-CoV-2 replication in these cells [3]. The effect of PDZ partner knockdown on virus replication was assessed in three independent experiments (each done in triplicate) and compared to virus replication in control siRNA-transfected cells (two-way ANOVA with Dunnett's test). As expected, knockdown of the SARS-CoV-2 receptor ACE2 resulted in significantly lower virus replication (Fig. 4). Virus replication was also significantly reduced in PARD3 and RSG3 knocked-down cells, suggesting a pro-viral role for these human proteins. PARD3 is found in our holdup assays as a PDZ partner of E protein of SARS-CoV, SARS-CoV-2, and MERS-CoV while RGS3 is recognized by SARS-CoV-2 3a protein. Comparatively, knockdown of MLLT4, PARD3B, MAST2, RHPN2, and HTRA generated an increased virus replication. MLLT4, MAST2, and HTRA1 interact with SARSCoV-2 E protein, PARD3B with SARS-CoV-2 3a protein, and finally RHPN2 binds to SARS-CoV-2 N protein.

Altogether, our results suggested that the expression of these seven proteins is relevant for viral replication. 
Table 2. Cellular PDZ-containing proteins recognized by at least one SARS-CoV-2 protein in holdup assays. List of the 20 PDZ partners of SARS-CoV-2 proteins selected for knockdown by siRNA transfection in human lung A549 cells. (+) indicated PDZ partners identified by assay with binding affinity values higher than 0.2 ; $(+/-)$ represented PDZ binders with $\mathrm{BI}$ values comprised between $0.16(105 \mu \mathrm{m})$ and $0.20(80 \mu \mathrm{M})$.

\begin{tabular}{|c|c|c|c|c|c|}
\hline \multirow[b]{2}{*}{$\begin{array}{l}\text { Name } \\
\text { prot }\end{array}$} & \multirow[b]{2}{*}{ Name gene } & \multirow[b]{2}{*}{ Gene id } & \multicolumn{3}{|c|}{ SARS-CoV-2 } \\
\hline & & & $\begin{array}{l}\text { Protein } \\
\text { E }\end{array}$ & $\begin{array}{l}\text { Protein } \\
3 a\end{array}$ & $\begin{array}{l}\text { Protein } \\
\mathrm{N}\end{array}$ \\
\hline TJP1 & TJP1/ZO1 & 7082 & + & + & \\
\hline PTPN13 & PTPN13 & 5783 & + & & \\
\hline HTRA1 & HTRA1 & 5654 & + & & \\
\hline MLLT4 & AFDN & 4301 & + & & \\
\hline PARD3 & PARD3 & 56288 & + & $+/-$ & \\
\hline NHERF1 & SLC9A3R1 & 9368 & + & & \\
\hline LNX2 & LNX2 & 222484 & + & & \\
\hline MAST2 & MAST2 & 23139 & + & & \\
\hline SNX27 & SNX27 & 81609 & + & & \\
\hline RADIL & RADIL & 55698 & + & & \\
\hline NHERF4 & PDZD3 & 79849 & & + & \\
\hline RGS3 & RGS3 & 5998 & & + & \\
\hline PARD3B & PARD3B & 117583 & & + & \\
\hline RHPN2 & RHPN2 & 85415 & & & + \\
\hline GIPC1 & GIPC1 & 10755 & & & + \\
\hline MPP5 & $\begin{array}{l}\text { MPP5/ } \\
\text { PALS1 }\end{array}$ & 64398 & $+1-$ & & \\
\hline FRMPD4 & FRMPD4 & 9758 & $+1-$ & $+/-$ & \\
\hline PDZD2 & PDZD2 & 23037 & $+1-$ & & \\
\hline DLG3 & DLG3 & 1741 & $+1-$ & & \\
\hline NHERF3 & PDZK1 & 5174 & & + & \\
\hline
\end{tabular}

\section{Discussion}

Only a few partners of SARS-CoV-2 E protein have been identified through extensive high-throughput approaches such as proteomics. As an example, among the structural SARS-CoV-2 proteins, only 6 binders of $\mathrm{E}$ protein are found as monitored in the Gordon et al. [3] study, while 30 partners for M protein and 15 binders to $\mathrm{N}$ protein are identified. Among them, no PDZ-containing protein has been identified in this study. Here, we have focused on specific interactions involving short C-terminal motifs of SARSCoV-2 proteins, the PBMs, and PDZ domains of human partners. We mainly used the holdup highthroughput screening to identify the host PDZ partners of $\mathrm{E}, 3 \mathrm{a}$, and $\mathrm{N}$ proteins and to quantify their PDZ-PBM affinities and specificities [19]. This chromatographic assay in solution is fully suitable to reliably rank low affinity interactions in the submillimolar range, which may escape detection by other highthroughput methods.

\section{Conservation of the PBM sequence in Coronavirus E protein}

The PBM motif at the $\mathrm{C}$ terminus of $\mathrm{E}$ protein is only expressed by coronaviral genera $\alpha$ and $\beta$, and is absent from the genus $\gamma$. The last 4 residues of $\mathrm{E}$ protein are strictly conserved in the SARS-CoV and SARS-CoV-2 viruses. A recent study has shown that, among the 3617 available complete genome sequences of SARSCoV-2 in the NCBI database, only two variants (DFLV and YLLV) have been reported in the DLLV PBM motif of the E protein [27].

Both the E proteins of SARS-CoV-2 and MERS$\mathrm{CoV}$ comprised putative PBM sequences at their $\mathrm{C}$ terminus but their nature is very different with a class II PBM for the genus $\alpha$, and a class III PBM for the genus $\beta$. Our work shows that despite the absence of conservation between the PBM sequence of SARS$\mathrm{CoV} / \mathrm{CoV}-2$ and MERS-CoV $\mathrm{E}$ protein, the two motifs interact with a common set of host partners; indeed, among the 10 host partners we identified for SARS-CoV-2, six are also binders of MERS-CoV.

\section{Host-viral protein-protein interactions}

\section{Comparison of host partners of $\mathrm{CoV}$ and $\mathrm{CoV}-2$}

The affinity-based ranking of the identified binders of E protein provided a specificity profile. As comparison, the class I PBMs of NS5 protein from West Nile virus (WNV) and of capsid protein from hepatitis B virus interact with 29 and 28 PDZ binders [25,28], respectively, while about $50 \mathrm{PDZ}$ proteins bind to the class I PBM of E6 viral oncoprotein from HPV16 [19]. By contrast, class II PBMs generally display lower affinities for their target and consequently a lowest number of binders in comparison with the class I PBMs. The hydrophobic character of the class II PBM sequences can explain the low affinities and sharp profiles of binding of SARS-CoV (seven binders) and SARS-CoV-2 (10 binders) E protein PBM with a reduced enthalpic contribution to the binding compared to the more hydrophilic class I sequences. Interestingly, the PBM of SARS-CoV-2 E protein can accommodate different classes of PDZ domains as illustrated in Fig. 5.

In the case of the class III PBM of E protein for MERS-CoV, the large number of targets (29) can be mainly explained by the presence of a tryptophan residue at position -1 , a residue known to have a strong contribution to the binding affinity [29], potentially at the expense of the specificity. The PBM upstream sequence might also have a contribution to the 


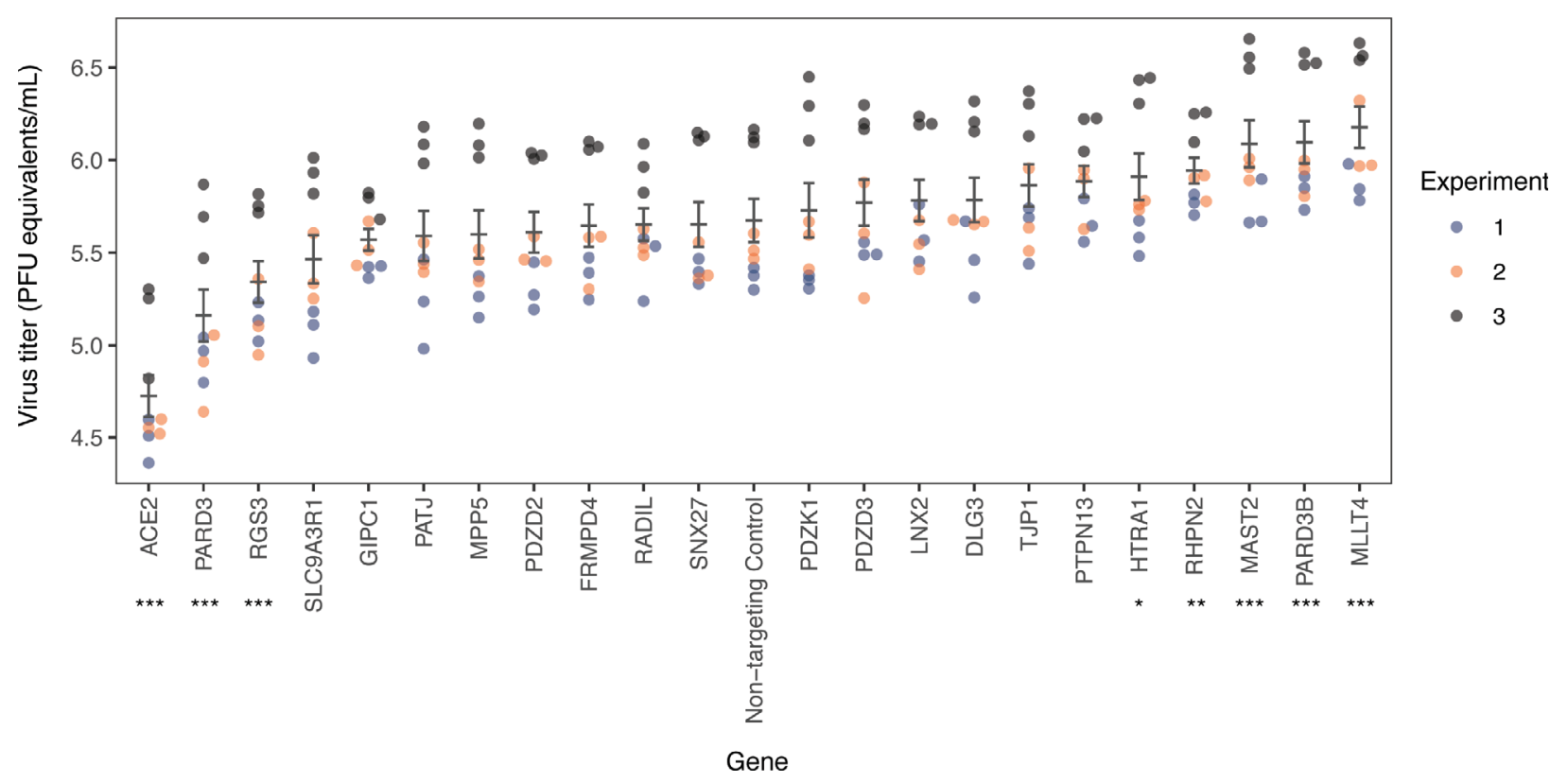

Fig. 4. Effect of knockdown of human PDZ-containing proteins on SARS-CoV-2 replication. The indicated genes were knocked down by siRNA transfection in human lung A549-ACE2 cells. ACE2 knockdown was used as a positive control. Virus load in knocked-down cells was assessed in three independent experiments (each done in triplicate) $72 \mathrm{~h}$ postinfection and is shown as PFU equivalents. $\mathrm{mL}^{-1}$ supernatant. The virus load in each condition was compared to that in control siRNA-transfected cells (two-way ANOVA with Dunnett's test for multiple comparisons $* * * P \leq 0.001 ; * * P=0.00611 ; * P=0.02672$ ). The data are representative of three independent experiments (each done in triplicate) and error bars correspond to the standard deviation of the three independent experiments.

extended profile of interaction of MERS-CoV E PBM peptide against the PDZome in the holdup assay. We have previously proposed that the large number of cell proteins targeted by WNV motif identified by holdup assay could be related to the broad host repertoire of flaviviruses replicating in very different cells and species necessary for its complex zoonotic transmission cycle. By contrast, SARS-CoV viruses infect very specialized cells, such as bronchial epithelial cells, pneumocytes, and upper respiratory tract cells in humans [30]. This observation can at least partially explain the narrow number of host proteins specifically targeted by SARS-CoV-2 during infection.

Six of the seven host PDZ partners of SARS-CoV E protein are also binders of SARS-CoV-2 E protein, in agreement with the strict conservation of their PBMs. However, the differences of sequence upstream the PBM enlarge the number of binders for SARSCoV-2 protein $\mathrm{E}$ with four more host partners (Fig. 1A). Our results suggest that the SARS-CoV/ SARS-CoV-2 PBM upstream sequence difference is responsible of the different binding profiles against the human PDZome. A few studies indicate that residues up to the upstream eleventh position (p-11) can also be implicated in PDZ binding by modulating the affinity $[29,31]$. Thus, we can hypothesize that the substitution of Arg (p-6 in SARS-CoV sequence) by Glu (p-7 in SARS-CoV-2 sequence) may affect the potential electrostatic interaction of $E$ protein with the $\beta 2$ $\beta 3$ loop of some PDZ domains. Interestingly, it has been reported that the substitution of a Glu at position -5 with Arg in the inward rectifier $\mathrm{K}(+)$ channel protein GIRK3 disrupts its interaction with the PDZ domain of SNX27 [32]. Here, we also observed that SNX27 binds to SARS-CoV-2 E protein exposing an Arg at p-7, while SARS-CoV E protein coding for Glu at p-6 does not. This example illustrates the fine tuning of the affinity/specificity profiles by the four residues of the PBM and the upstream sequence. Therefore, the charged residue substitution between SARS-CoV and SARS-CoV-2 PBM can modify the selective association of host PDZ proteins with the viral protein. The four host PDZ proteins, SNX27, RADIL, NHERF1, and MAST2 recognized by SARS-CoV-2, and not by SARS-CoV, can play a role in the differences observed between the two infections. The role of these PDZ proteins in viral pathogenesis remains to be explored. 


\begin{tabular}{|l|l|l|}
\hline PDZ domain & PDB code & $\begin{array}{l}\alpha 2 \text { residue } \\
\text { facing } \text {-2 }\end{array}$ \\
\hline TJP1-2 & 2JWE & Leu \\
\hline NHERF1-2 & 2OZF & Tyr \\
\hline PTPN13-4 & c2qg1A* & His \\
\hline HTRA1 & 2YTW & Ala \\
\hline MAST2 & 2KYL & His \\
\hline LNX2-2 & 2VWR & Pro \\
\hline PARD3-3 \# & 2K1Z & Asn \\
\hline SNX27 & 6SAK & His \\
\hline RADIL & 1UM1 & Tyr \\
\hline $\begin{array}{l}\text { MLLT4 } \\
\text { *Phyre2 model } \\
\text { Human sequences excepted }\end{array}$ & 1T2M & Gln \\
\hline
\end{tabular}

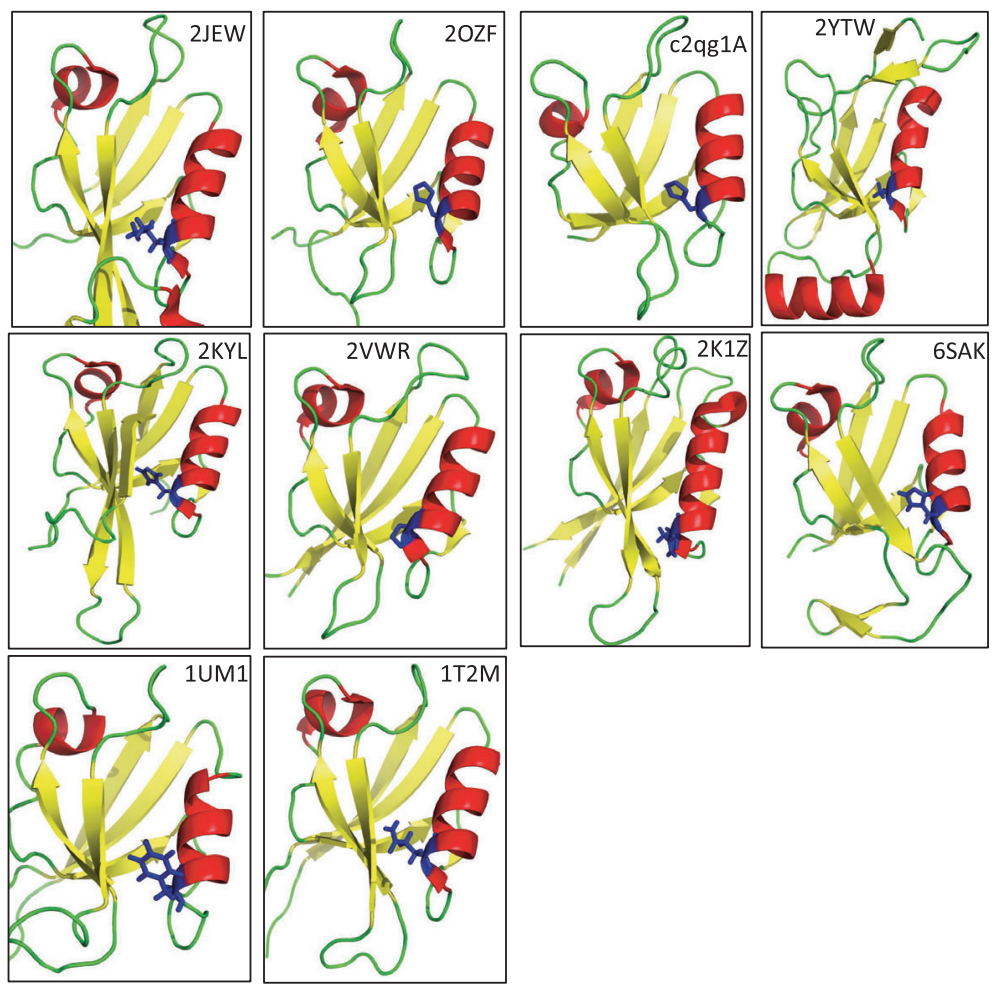

Fig. 5. Classes of PDZ domains targeted by the SARS-CoV-2 E protein PBM. Left panel: name of selected PDZ domain, PDB code of their structure and the residue of PDZ helix $\alpha 2$ in interaction with p-2 of PBM. Right panel: structural view of the PBM binding groove with the residue of helix $\alpha 2$ facing $\mathrm{p}-2$ of PBM highlighted in blue sticks. *Phyre2 model. Human sequences excepted \# from Rattus norvegicus

\section{Functions of host partners of SARS E protein}

Among the five host proteins already reported as protein E partners (Schoeman et al., 2020) [33], syntenin/ SCDP and MPP5/PALS1 encode for a PBM potentially involved in PDZ binding. We did not detect the interaction between syntenin PDZ domain and SARSCoV-2 E protein. With the holdup assay, we measured a weak interaction between MPP5/PALS1 PDZ domain and SARS-CoV-2 E PBM [dissociation constant $\left(K_{\mathrm{d}}\right)$ of $102 \mu \mathrm{M}$ ], while we did not detect interaction between MPP5/PALS1 PDZ domain and SARS$\mathrm{CoV}$ E PBM. Using equilibrium binding titration in vitro by Förster Resonance Energy Transfer (FRET), Toto and collaborators [34] have also calculated a better affinity of SARS-CoV-2 for MPP5/ PALS1, illustrating the potential role of the upstream substitutions observed in the SARS-CoV-2 C-terminal E protein sequence in comparison with the SARS-CoV one. Teoh and collaborators [18] have proposed that this interaction between SARS-CoV E protein and MPP5/PALS1 alters the tight junctions in the lungs, MPP5/PALS1 being a key component of the Crumbs complex that controls the apical-basal polarity and tight junction formation. We cannot exclude that the rest of MPP5 and E proteins are required to stabilize their complex, as well as for syntenin that is reported to bind the $\mathrm{E}$ protein by strategies using full-length proteins (yeast two-hybrid, reciprocal coimmunoprecipitation and confocal microscopy assays).

Remarkably, we pinpointed that most of binding proteins are involved in cellular junctions and polarity, cellular trafficking, and signaling. Indeed, our results highlighted that SARS-CoV-2 targets several proteins of the apical complex and tight/adherens junctions. Consequently, we expect that the SARS-CoV-2 proteins $\mathrm{E}, 3 \mathrm{a}$, and $\mathrm{N}$ can contribute to globally affect the cellular junctions and cellular polarity. We identified TJP1 as the best binder for $\mathrm{E}$ and $3 \mathrm{a}$ proteins. TJP proteins, also called $\mathrm{ZO}$ proteins, provide a network of scaffold proteins that tether the TM tight junction proteins, comprising the Claudins, to the actin cytoskeleton [35]. The three TJP paralogous proteins, TJP1, TJP2, and TJP3, encode for three PDZ domains in their $\mathrm{N}$-terminal region. In our in vitro assay, the 
second PDZ of TJP1 displays the highest affinity for E and 3a proteins of SARS-CoV-2 in the micromolar range. This domain has been previously described as the binding site of TJP1 for the connexin43 [36], involved in the organization of the gap junction, but also in the ZO-2 and ZO-3 hetero-association. Dimerization of TJP1 occurs through the interaction between TJP1-PDZ2 domains and the swapped-dimerization of TJP1-PDZ2 regulates the connexin-43 binding [37]. Interestingly, TJP proteins also interact with Afadin/ MLLT4 while the PBM sequence of TJP2 binds to the PDZ domain of SNX27 to regulate the trafficking of TJP2 to the tight junction [38,39]. PARD3 is also involved in the formation of adherens and tight junctions. Here, we showed that MLLT4, SNX27, PARD3, and MPP5/PALS1 to a lesser extent are also targeted by SARS-CoV-2 E PBM. By interacting by at least five proteins directly involved in the organization of the tight junction complexes, we expect a global perturbation of the epithelial/endothelial barriers by SARS-CoV-2 during infection. In this direction, SARS-CoV-2 replication causes a transient decrease in cellular barrier function and disruption of tight junctions [40] and a SARS-CoV-2 productive infection locally alters the distribution of TJP1, which associates to tight junctions. The characteristic TJP1 staining pattern at cell boundaries appeared disrupted in areas with viral expression, suggesting a possible impairment of epithelial barrier integrity [40].

Targeting host proteins from polarity and junctions complexes may have a consequence on the morphology of epithelium/endothelium but also on the immune response and cellular homeostasis [41]. In addition to their structural role in many tissues and organs, they can also regulate signaling mechanisms. Tight junctions are linked to many human diseases. Therefore, chronic inflammatory diseases and cancer have been related to dysfunction of tight junctions. MPP5/PALS1 of the Crumbs complex is expressed in T lymphocytes and is required for the T-cell receptor (TCR)-mediated activation [42]. TJP1 and TJP2 are also expressed in T lymphocytes and are relocated to the immune synapse after TCR stimulation. SNX27 regulates trafficking and recycling in $\mathrm{T}$ lymphocytes and controls TJP2 mobility at the immune synapse through a PDZ-dependent interaction [43]. LNX1/2 is involved in signaling with involvement in ubiquitination subsequent proteasomal degradation. The PDZ3 domain of PARD3 binds to the transcription factor YAP (Yes-associated protein) [44] regulating the activation of the Hippo pathway, a signaling pathway modulating cell proliferation and cell death. YAP protein can be found associated to the adherens and tight junctions and several regulators of Hippo pathway are components of the adherens and tight junctions [45]. Finally, NHERF1 regulates the Wnt/b-catenin signaling, a pathway that controls cell growth and proliferation. NHERF1 has been shown to be targeted for degradation by E6 from HPV [46]. RHPN2 (Rho pathway; [47]), MAST2 (anti-survival pathway, PTEN/Akt signaling; [12]), RGS3 (G protein signaling; [48]), PTPN13 (tumor suppressor, Akt signaling; [49]), and HTRA1 (Signaling pathway TGF- $\beta$; [50]) play also function in signaling pathways. All these proteins have been found to significantly interact with SARS-CoV-2 proteins in our holdup assay. Seven of the 14 host targets of SARS-CoV-2 proteins $\mathrm{E}, 3 \mathrm{a}$, and $\mathrm{N}$ significantly impacted viral replication. We showed that knockdown of the PDZ-containing proteins PARD3 and RSG3 results in a decrease of SARS-CoV-2 replication in cells while the silencing of MLLT4, PARD3B, MAST2, RHPN2, and HTRA1 increases virus replication. These proteins are involved in the regulation of cellular junction and polarity, but also in cellular signaling. However, we cannot conclude on the PDZ/PBM dependence of this result, and further, in cell studies are needed to decipher the functional role of these proteins in the viral cycle of SARS-CoV-2.

\section{PDZ proteins recognized by SARS-CoV-2 E protein are also host targets of other viruses}

Many studies provide structural and biological evidence that the viral proteins act as competitors endowed with specificity and affinity in an essential cellular process by mimicking PBM of cellular partners. Disruption of critical endogenous protein-protein interactions by viral protein drastically alters intracellular protein trafficking and catalytic activity of cellular proteins that control cell homeostasis. Importantly, most of our selected host PDZ-containing proteins have been previously reported as host proteins targeted by viruses. Tight junctions are known to be targeted by multiple pathogenic viruses [51,52]. PARD3 and TJP1 are targets of flavivirus proteins (WNV, tickborne encephalitis virus, and Dengue virus) $[28,53,54,55]$. Others cellular PDZ proteins were also identified as targets for other virus including DLG1 for hepatitis C virus and influenza virus [56,57]; NHERF1, HTRA1, PARD3, SNX27 for HPV $[46,58,59,60]$.

Here, we showed that the three viral PBM-containing proteins expressed by SARS-CoV-2 target several cellular proteins involved in the maintenance and regulation of the tight junctions and immune response. By hijacking junctional proteins and signaling 
mechanisms, viruses ensure their propagation through the manipulation of the cellular homeostasis, the immune system, and tissue barriers. The perturbation of cellular fitness promotes their replication and spread. Many PDZ-containing proteins are involved in cell-cell junctions, cell polarity, recycling, or trafficking. Mimicking short linear PBM motifs to target PDZ protein and subvert host functionality is a high adaptation capacity and a significant evolutionary advantage of many viruses [41]. We previously showed that the PBM from the glycoprotein encoded by the rabies virus competes with PTEN for binding to the anti-survival kinase MAST2 and drastically affects the PTEN/Akt signaling pathway. Consequently, the viral glycoprotein/MAST2 interaction promotes survival of the infected neurons to ensure viral propagation. As already observed for other viruses, potential pleiotropic perturbation of cellular functions can be induced by SARS-CoV-2 during infection comprising cell survival/death (MAST2, PARD3, NHERF1), immune response (MPP5/PALS1, syntenin), and cellular organization (TJP1, MLLT4).

\section{Materials and methods}

\section{Peptide synthesis}

The peptides were synthesized in solid phase using Fmoc strategy (Proteogenix, Schiltigheim, France) encompassing a biotinyl group, a $(\mathrm{PEG})_{3}$ or 6-aminohexanoic acid (Ahx) spacer, and the $\mathrm{C}$-terminal $\mathrm{PBM}$ sequence of $\mathrm{E}, 3 \mathrm{~A}$, and $\mathrm{N}$ proteins (12 residues long). Peptides were resuspended in water or in a mix of DMSO and buffer and used for holdup and competitive fluorescence polarization assays.

\section{Holdup assays}

We used an updated version of our original PDZome library [19], that contains 266 soluble PDZs [20]. This PDZome v2 library was prepared as previously described [20].

The holdup assay was carried out with the biotinylated viral PBMs against the full human PDZ library in two independent experiments [19,20]. Error bars are standard deviations of the two experiments. In brief, we measured the fraction of PDZ depletion in the fluid phase during a pull-down experiment. For the detailed protocol, please look at [20]. All His6-MBP-PDZ constructs were expressed in $E$. coli following the previous protocol [19] with minimal modifications and cell lysate soluble fractions of all constructs were adjusted to approximately $4 \mu \mathrm{M}$ concentration using a microcapillary electrophoretic system (Caliper; PerkinElmer, Waltham, MA, USA) and frozen in 96-well plates. Streptavidin resin was saturated with biotinylated
PBM peptides or with biotin used as a negative control. PDZ-containing cell lysates were incubated with the resins, and the supernatant was separated from the resin by a fast filtration step using filter plates. PDZ concentrations were evaluated using the microcapillary electrophoretic system and $\mathrm{BI}$ values were calculated using BI $=($ Itot-Idepl) $/$ Itot, where Itot is the total intensity of the PDZ peak (biotin control) and Idepl is the intensity of PDZ peak in the peptide depleted reaction. In the holdup buffer, lysozyme was used as internal standard for peak intensity normalization. $\mathrm{BI}=0.2$ was used as the minimal $\mathrm{BI}$ threshold value to define high-confidence PDZ-PBM pairs, as proposed previously [19]. For the detailed protocols of production and quality control, please look at [20].

Affinity values (Fig. 1, Table 1 and Table S1) were calculated from the BIs according to the method published in Gogl et al. [23]. Immobilized peptide concentrations were calculated using measured dissociation constants from competitive fluorescent polarization assays (see below). We have found that all determined $\mathrm{BI}-K_{\mathrm{d}}$ pairs resulted a mean peptide concentration of $\sim 20 \mu \mathrm{M}$, a concentration that is coherent with other peptides in the same method $[22,23,61]$. The minimal BI threshold value is 0.2 to define a significant interaction, roughly corresponding to a $100 \mu \mathrm{M}$ dissociation constant as previously reported [19].

\section{Competitive fluorescence polarization assay}

Competitive fluorescence polarization measurement and data evaluation were performed as described by Simon and collaborators [62]. Four different fluorescent peptides were used f16E6 (fluorescein-RTRRETQL), fRSK1 (fluoresceinKLPSTTL), fpRSK1 (fluorescein-KLPpSTTL), and MERS-CoV. The MERS-CoV peptide was labeled with sub-stoichiometric FITC (Sigma-Aldrich, St. Louis, MO, USA) in a basic HEPES buffer ( $\mathrm{pH} 8.2$ ), and the reaction was stopped with $100 \mathrm{~mm}$ TRIS. The peptide was buffer exchanged in order to remove fluorescent contaminants. Fluorescence polarization was measured with a PHERAstar (BMG Labtech, Offenburg, Germany) microplate reader by using $485 \pm 20$ and $528 \pm 20 \mathrm{~nm}$ band-pass filters (for excitation and emission, respectively). In direct FP measurements, a dilution series of the Ni- and Amylose-affinity purified MBP-PDZ proteins was prepared in a $20 \mathrm{~mm}$ HEPES pH 7.5 buffer that contained $150 \mathrm{~mm} \mathrm{NaCl}$, $0.5 \mathrm{~mm}$ TCEP, $0.01 \%$ Tween 20 , and $50 \mathrm{~nm}$ fluorescently labeled peptide. In total, the polarization of the probe was measured at 8 different protein concentrations. In competitive FP measurements, the same buffer was supplemented with the protein to achieve a complex formation of 60 $80 \%$, based on the direct titration. Then, this mixture was used for creating a dilution series of the competitor (i.e., the studied peptides) and the measurement was carried out identically as in the direct experiment. Analysis of FP experiments was carried out using ProFit. 


\section{Cells}

A549 cells stably expressing ACE2 (A549-ACE2, kindly provided by $\mathrm{O}$. Schwartz) were propagated at $37{ }^{\circ} \mathrm{C}, 5 \%$ $\mathrm{CO}_{2}$ in DMEM with L-glutamine (Gibco, Co Dublin, Ireland) supplemented with $10 \%$ FBS, penicillin-streptomycin, and $20 \mu \mathrm{g} \cdot \mathrm{mL}^{-1}$ blasticidin $\mathrm{S}$.

\section{Virus}

The SARS-CoV-2 strain used (BetaCoV/France/IDF0372/ 2020 strain) is a kind gift from the National Reference Centre for Respiratory Viruses at Institut Pasteur, Paris, originally supplied through the European Virus Archive goes Global platform. It was propagated once in Vero-E6 cells.

\section{siRNA transfections}

An OnTargetPlus siRNA SMARTpool library (Horizon Discovery, Waterbeach, UK) was purchased targeting 20 human PDZ-containing proteins (Table S2). This library was arrayed in 96-well format and also included nontargeting siRNAs and siRNA pools targeting ACE2. The siRNA library was transfected into A549-ACE2 cells seeded in a 384-well plate format (6250 cells per well), using Lipofectamine RNAiMAX reagent (Thermo Fisher, Waltham, MA, USA).

Briefly, 4 pmoles of each siRNA pool were mixed with $0.1 \mu \mathrm{L}$ RNAiMAX transfection reagent and OptiMEM (Thermo Fisher) in a total volume of $10 \mu \mathrm{L}$. After a 5-min incubation period, the transfection mix was added to cells. Forty-eight hours post-transfection, the cells were either subjected to SARS-CoV-2 infection or incubated for $72 \mathrm{~h}$ to assess cell viability using the CellTiter-Glo luminescent viability assay, following the manufacturer's instructions (Promega, Madison, WI, USA). Luminescence was measured in a Tecan Infinity 2000 plate reader, and percentage viability calculated relative to untreated cells $(100 \%$ viability) and cells lysed with $20 \%$ ethanol or $4 \%$ formalin $(0 \%$ viability), included in each experiment.

\section{Virus infections}

For infections, the cell culture medium was replaced with virus inoculum [MOI 0.1 plaque forming units (PFU) per cell)] and incubated for $1 \mathrm{~h}$ at $37{ }^{\circ} \mathrm{C}, 5 \% \mathrm{CO}_{2}$. After $1 \mathrm{~h}$ adsorption period, the inoculum was removed, replaced with fresh media, and cells incubated at $37^{\circ} \mathrm{C}, 5 \% \mathrm{CO}_{2}$. $72 \mathrm{~h}$ postinfection, the cell culture supernatant was harvested, and viral load assessed by RT-qPCR. Briefly, the cell culture supernatant was collected, heat inactivated at $95{ }^{\circ} \mathrm{C}$ for $5 \mathrm{~min}$, and used for RT-qPCR analysis. SARSCoV-2 specific primers targeting the $\mathrm{N}$ gene region: $5^{\prime}-$ TAATCAGACAAGGAACTGATTA-3' (Forward) and 5'-
CGAAGGTGTGACTTCCATG-3' (Reverse) were used with the Luna Universal One-Step RT-qPCR Kit (New England Biolabs, Courcouronnes, France) in an Applied Biosystems QuantStudio 6 thermocycler, with the following cycling conditions: $55^{\circ} \mathrm{C}$ for $10 \mathrm{~min}, 95^{\circ} \mathrm{C}$ for $1 \mathrm{~min}$, and 40 cycles of $95{ }^{\circ} \mathrm{C}$ for 10 seconds, followed by $60{ }^{\circ} \mathrm{C}$ for $1 \mathrm{~min}$. The number of viral genomes is expressed as PFU equivalents $\cdot \mathrm{mL}^{-1}$ and was calculated by performing a standard curve with RNA derived from a viral stock with a known viral titer. The effect of knockdowns on virus replication was compared to control siRNA-transfected cells in three independent experiments (each done in triplicate) with Dunnett's multiple comparison test based on a two-way ANOVA.

\section{Acknowledgements}

This work was supported by the URGENCE COVID19 fundraising campaign of Institut Pasteur, the ANR Recherche Action Covid19-FRM PDZCov2 program and by the French Infrastructure for Integrated Structural Biology (FRISBI) ANR-10-INSB-05-01 for AFMB. GG is a recipient of the Post-doctorants en France program of the Fondation ARC fellowship. The authors acknowledge Gilles Travé for helpful discussion and for proofreading of the manuscript.

\section{Conflict of interest}

The authors declare no conflict of interest.

\section{Author contributions}

CC-S, RV, and NW planned the experiments. CC-S, FD, VVR, and GG performed the experiments. CC-S, FD, VVR, GG, QDT, RV, and NW analyzed the data. J-CT and MV contributed reagents or other essential material. CC-S, RV, and NW wrote the paper.

\section{Peer Review}

The peer review history for this article is available at https://publons.com/publon/10.1111/febs.15881.

\section{References}

1 Su S, Wong G, Shi W, Liu J, Lai ACK, Zhou J, Liu W, Bi Y \& Gao GF (2016) Epidemiology, genetic recombination, and pathogenesis of coronaviruses. Trends Microbiol 24, 490-502.

2 Petersen E, Koopmans M, Go U, Hamer DH, Petrosillo N, Castelli F, Storgaard M, Al Khalili S \& 
Simonsen L (2020) Comparing SARS-CoV-2 with SARS-CoV and influenza pandemics. Lancet Infect Dis 20, e238-e244.

3 Gordon DE, Jang GM, Bouhaddou M, Xu J, Obernier K, White KM, O'Meara MJ, Rezelj VV, Guo JZ, Swaney DL et al. (2020) A SARS-CoV-2 protein interaction map reveals targets for drug repurposing. Nature 583, 459-468.

4 Stukalov A, Girault V, Grass V, Bergant V, Karayel O, Urban C, Haas DA, Huang Y, Oubraham L, Wang A et al. (2020) Multi-level proteomics reveals hostperturbation strategies of SARS-CoV-2 and SARSCoV. bioRxiv [PREPRINT]

5 Bojkova D, Klann K, Koch B, Widera M, Krause D, Ciesek S, Cinatl J \& Münch C (2020) Proteomics of SARS-CoV-2-infected host cells reveals therapy targets. Nature 583, 469-472.

6 Weatheritt RJ, Luck K, Petsalaki E, Davey NE \& Gibson TJ (2012) The identification of short linear motif-mediated interfaces within the human interactome. Bioinformatics 28, 976-982.

7 Davey NE, Travé G \& Gibson TJ (2011) How viruses hijack cell regulation. Trends Biochem Sci 36, 159169.

8 Liu X \& Fuentes EJ (2019) Emerging themes in PDZ domain signaling: structure, function, and inhibition. Int Rev Cell Mol Biol 343, 129-218.

9 Christensen NR, Čalyševa J, Fernandes EFA, Lüchow S, Clemmensen LS, Haugaard-Kedström LM \& Strømgaard K (2019) PDZ domains as drug targets. Adv Ther (Weinh) 2, 1800143.

10 Javier RT \& Rice AP (2011) Emerging theme: cellular PDZ proteins as common targets of pathogenic viruses. J Virol 85, 11544-11556.

11 Caillet-Saguy C, Maisonneuve P, Delhommel F, Terrien E, Babault N, Lafon M, Cordier F \& Wolff N (2015) Strategies to interfere with PDZ-mediated interactions in neurons: what we can learn from the rabies virus. Prog Biophys Mol Biol 119, 53-59.

12 Terrien E, Chaffotte A, Lafage M, Khan Z, Préhaud C, Cordier F, Simenel C, Delepierre M, Buc H, Lafon M et al. (2012) Interference with the PTEN-MAST2 interaction by a viral protein leads to cellular relocalization of PTEN. Sci Signal 5, ra58.

13 Maisonneuve P, Caillet-Saguy C, Vaney M-C, Edoo BZ, Sawyer K, Raynal B, Delepierre M, Lafon M, Cordier F \& Wolff N (2016) Molecular basis of the interaction of the human protein tyrosine phosphatase non-receptor type 4 (PTPN4) with the mitogenactivated protein kinase p38 $\gamma$. J Biol Chem 291, 16699 16708 .

14 Li Y, Surya W, Claudine S \& Torres J (2014) Structure of a conserved Golgi complex-targeting signal in coronavirus envelope proteins. J Biol Chem 289, 1253512549 .
15 Ruch TR \& Machamer CE (2012) The coronavirus E protein: assembly and beyond. Viruses 4, 363-382.

16 Schoeman D \& Fielding BC (2019) Coronavirus envelope protein: current knowledge. Virol J 16, 69.

17 Jimenez-Guardeño JM, Nieto-Torres JL, DeDiego ML, Regla-Nava JA, Fernandez-Delgado R, CastañoRodriguez C \& Enjuanes L (2014) The PDZ-binding motif of severe acute respiratory syndrome coronavirus envelope protein is a determinant of viral pathogenesis. PLoS Pathog 10, e1004320.

18 Teoh K-T, Siu Y-L, Chan W-L, Schlüter MA, Liu C-J, Peiris JSM, Bruzzone R, Margolis B \& Nal B (2010)

The SARS coronavirus E protein interacts with PALS1 and alters tight junction formation and epithelial morphogenesis. Mol Biol Cell 21, 3838-3852.

19 Vincentelli R, Luck K, Poirson J, Polanowska J, Abdat J, Blémont M, Turchetto J, Iv F, Ricquier K, Straub M-L et al. (2015) Quantifying domain-ligand affinities and specificities by high-throughput holdup assay. Nat Methods 12, 787-793.

20 Duhoo Y, Girault V, Turchetto J, Ramond L, Durbesson F, Fourquet P, Nominé Y, Cardoso V, Sequeira AF, Brás JLA et al. (2019) High-throughput production of a new library of human single and tandem PDZ domains allows quantitative PDZ-peptide interaction screening through high-throughput holdup assay. Methods Mol Biol 2025, 439-476.

21 Amacher JF, Brooks L, Hampton TH \& Madden DR (2020) Specificity in PDZ-peptide interaction networks: computational analysis and review. J Struct Biol X 4, 100022.

22 Jané P, Gógl G, Kostmann C, Bich G, Girault V, Caillet-Saguy C, Eberling P, Vincentelli R, Wolff N, Travé $\mathrm{G}$ et al. (2020) Interactomic affinity profiling by holdup assay: acetylation and distal residues impact the PDZome-binding specificity of PTEN phosphatase. PLoS One 15, e0244613.

23 Gogl G, Jane P, Caillet-Saguy C, Kostmann C, Bich G, Cousido-Siah A, Nyitray L, Vincentelli R, Wolff N, Nomine Y et al. (2020) Dual specificity PDZ- and 14-33-binding motifs: a structural and interactomics study. Structure 28, 747-759.e3.

24 Castaño-Rodriguez C, Honrubia JM, Gutiérrez-Álvarez J, DeDiego ML, Nieto-Torres JL, Jimenez-Guardeño JM, Regla-Nava JA, Fernandez-Delgado R, VerdiaBáguena C, Queralt-Martín M et al. (2018) Role of severe acute respiratory syndrome coronavirus viroporins $\mathrm{E}, 3 \mathrm{a}$, and $8 \mathrm{a}$ in replication and pathogenesis. MBio 9, 1-23.

25 Genera M, Quioc-Salomon B, Nourisson A, Colcombet-Cazenave B, Haouz A, Mechaly A, Matondo M, Duchateau M, König A, Windisch MP et al. (2021) Molecular basis of the interaction of the human tyrosine phosphatase PTPN3 with the hepatitis B virus core protein. Sci Rep 11, 944. 
26 Buchrieser J, Dufloo J, Hubert M, Monel B, Planas D, Rajah MM, Planchais C, Porrot F, Guivel-Benhassine F, Van der Werf S et al. (2020) Syncytia formation by SARS-CoV-2-infected cells. EMBO J 39, e106267.

27 Hassan SS, Choudhury PP \& Roy B (2020) Molecular phylogeny and missense mutations at envelope proteins across coronaviruses. Genomics 112, 4993-5004.

28 Giraud E, Del Val CO, Caillet-Saguy C, Zehrouni N, Khou C, Caillet J, Jacob Y, Pardigon N \& Wolff N (2021) Role of PDZ-binding motif from West Nile virus NS5 protein on viral replication. Sci Rep 11, 3266.

29 Luck K, Charbonnier S \& Travé G (2012) The emerging contribution of sequence context to the specificity of protein interactions mediated by PDZ domains. FEBS Lett 586, 2648-2661.

30 V'kovski P, Kratzel A, Steiner S, Stalder H \& Thiel V (2020) Coronavirus biology and replication: implications for SARS-CoV-2. Nat Rev Microbiol 19, 155-170.

31 Delhommel F, Chaffotte A, Terrien E, Raynal B, Buc H, Delepierre M, Cordier F \& Wolff N (2015) Deciphering the unconventional peptide binding to the PDZ domain of MAST2. Biochem J 469, 159-168.

32 Balana B, Maslennikov I, Kwiatkowski W, Stern KM, Bahima L, Choe S \& Slesinger PA (2011) Mechanism underlying selective regulation of $\mathrm{G}$ protein-gated inwardly rectifying potassium channels by the psychostimulant-sensitive sorting nexin 27. Proc Natl Acad Sci USA 108, 5831-5836.

33 Schoeman D \& Fielding BC (2020) Is There a Link Between the Pathogenic Human Coronavirus Envelope Protein and Immunopathology? A Review of the Literature. Front Microbiol 11, 2086.

34 Toto A, Ma S, Malagrinò F, Visconti L, Pagano L, Stromgaard K \& Gianni S (2020) Comparing the binding properties of peptides mimicking the Envelope protein of SARS-CoV and SARS-CoV-2 to the PDZ domain of the tight junction-associated PALS1 protein. Protein Sci 29, 2038-2042.

35 Otani T \& Furuse M (2020) Tight junction structure and function revisited. Trends Cell Biol 30, 805-817.

36 Giepmans BN \& Moolenaar WH (1998) The gap junction protein connexin43 interacts with the second PDZ domain of the zona occludens-1 protein. Curr Biol 8, 931-934.

37 Chen J, Pan L, Wei Z, Zhao Y \& Zhang M (2008) Domain-swapped dimerization of ZO-1 PDZ2 generates specific and regulatory connexin 43 -binding sites. EMBO J 27, 2113-2123.

38 Rouaud F, Sluysmans S, Flinois A, Shah J, Vasileva E \& Citi S (2020) Scaffolding proteins of vertebrate apical junctions: structure, functions and biophysics. Biochim Biophys Acta Biomembr 1862, 183399.

39 Zimmerman SP, Hueschen CL, Malide D, Milgram SL \& Playford MP (2013) Sorting nexin 27 (SNX27) associates with zonula occludens-2 (ZO-2) and modulates the epithelial tight junction. Biochem $J \mathbf{4 5 5}$, 95-106.

40 Robinot R, Hubert M, de Melo GD, Lazarini F, Bruel T, Smith N, Levallois S, Larrous F, Fernandes J, Gellenoncourt S et al. (2020) SARS-CoV-2 infection damages airway motile cilia and impairs mucociliary clearance. bioRxiv [PREPRINT].

41 Gutiérrez-González LH \& Santos-Mendoza T (2019) Viral targeting of PDZ polarity proteins in the immune system as a potential evasion mechanism. FASEB J 33, 10607-10617.

42 Carvalho G, Poalas K, Demian C, Hatchi E, Vazquez A \& Bidère N (2011) Participation of the cell polarity protein PALS1 to T-cell receptor-mediated NF- $\kappa \mathrm{B}$ activation. PLoS One 6, e18159.

43 Tello-Lafoz M, Martínez-Martínez G, RodríguezRodríguez C, Albar JP, Huse M, Gharbi S \& Merida I (2017) Sorting nexin 27 interactome in T-lymphocytes identifies zona occludens-2 dynamic redistribution at the immune synapse. Traffic 18, 491-504.

44 Zhang $\mathrm{P}$, Wang S, Wang S, Qiao J, Zhang L, Zhang Z \& Chen Z (2016) Dual function of partitioningdefective 3 in the regulation of YAP phosphorylation and activation. Cell Discov 2, 16021.

45 Yu F-X \& Guan K-L (2013) The Hippo pathway: regulators and regulations. Genes Dev 27, 355-371.

46 Drews CM, Case S \& Pol SBV (2019) E6 proteins from high-risk HPV, low-risk HPV, and animal papillomaviruses activate the $\mathrm{Wnt} / \beta$-catenin pathway through E6AP-dependent degradation of NHERF1. PLoS Pathog 15, e1007575.

47 Danussi C, Akavia UD, Niola F, Jovic A, Lasorella A, Pe'er D \& Iavarone A (2013) RHPN2 drives mesenchymal transformation in malignant glioma by triggering RhoA activation. Cancer Res 73, 5140-5150.

48 Dunn HA \& Ferguson SSG (2015) PDZ protein regulation of $G$ protein-coupled receptor trafficking and signaling pathways. Mol Pharmacol 88, 624-639.

49 Long Q, Sun J, Lv J, Liang Y, Li H \& Li X (2020) PTPN13 acts as a tumor suppressor in clear cell renal cell carcinoma by inactivating Akt signaling. Exp Cell Res 396, 112286.

50 Li Y, Yuan J, Rothzerg E, Wu X, Xu H, Zhu S \& Xu J (2020) Molecular structure and the role of hightemperature requirement protein 1 in skeletal disorders and cancers. Cell Prolif 53, e12746.

51 Torres-Flores JM \& Arias CF (2015) Tight junctions go viral!. Viruses 7, 5145-5154.

52 Zihni C, Mills C, Matter K \& Balda MS (2016) Tight junctions: from simple barriers to multifunctional molecular gates. Nat Rev Mol Cell Biol 17, 564-580.

53 Ellencrona K, Syed A \& Johansson M (2009) Flavivirus NS5 associates with host-cell proteins zonula occludens1 (ZO-1) and regulating synaptic membrane exocytosis- 
2 (RIMS2) via an internal PDZ binding mechanism. Biol Chem 390, 319-323.

54 Melik W, Ellencrona K, Wigerius M, Hedström C, Elväng A \& Johansson M (2012) Two PDZ binding motifs within NS5 have roles in Tick-borne encephalitis virus replication. Virus Res 169, 54-62.

55 Werme K, Wigerius M \& Johansson M (2008) Tickborne encephalitis virus NS5 associates with membrane protein scribble and impairs interferon-stimulated JAKSTAT signalling. Cell Microbiol 10, 696-712.

56 Awad A, Sar S, Barré R, Cariven C, Marin M, Salles JP, Erneux C, Samuel D \& Gassama-Diagne A (2013) SHIP2 regulates epithelial cell polarity through its lipid product, which binds to Dlg1, a pathway subverted by hepatitis C virus core protein. Mol Biol Cell 24, 21712185.

57 Golebiewski L, Liu H, Javier RT \& Rice AP (2011) The avian influenza virus NS1 ESEV PDZ binding motif associates with Dlg1 and Scribble to disrupt cellular tight junctions. J Virol 85, 10639-10648.

58 Stuqui B, Conceição ALG, Termini L, Sichero L, Villa LL, Rahal P, de Calmon M \& Calmon MF (2016) The differential role of HTRA1 in HPV-positive and HPVnegative cervical cell line proliferation. BMC Cancer 16, 840.

59 Facciuto F, Bugnon Valdano M, Marziali F, Massimi P, Banks L, Cavatorta AL \& Gardiol D (2014) Human papillomavirus (HPV)-18 E6 oncoprotein interferes with the epithelial cell polarity Par3 protein. Mol Oncol 8, 533-543.
60 Ganti K, Massimi P, Manzo-Merino J, Tomaić V, Pim D, Playford MP, Lizano M, Roberts S, Kranjec C, Doorbar J et al. (2016) Interaction of the human papillomavirus E6 oncoprotein with sorting nexin 27 modulates endocytic cargo transport pathways. PLoS Pathog 12, e1005854.

61 Gógl G, Biri-Kovács B, Durbesson F, Jane P, Nomine Y, Kostmann C, Bilics V, Simon M, Reményi A, Vincentelli R et al. (2019) Rewiring of RSK-PDZ interactome by linear motif phosphorylation. $\mathrm{J} \mathrm{Mol}$ Biol 431, 1234-1249.

62 Simon MA, Ecsédi P, Kovács GM, Póti ÁL, Reményi A, Kardos J, Gógl G \& Nyitray L (2020) Highthroughput competitive fluorescence polarization assay reveals functional redundancy in the $\mathrm{S} 100$ protein family. FEBS $J$ 287, 2834-2846.

\section{Supporting information}

Additional supporting information may be found online in the Supporting Information section at the end of the article.

Table S1. All BI values obtained by holdup assay using PBM peptides from SARS-CoV, SARS-Cov-2, and MERS-CoV E proteins, and from SARS-CoV-2 $\mathrm{N}$ and $3 \mathrm{a}$ proteins.

Table S2. OnTargetPlus siRNA SMARTpool library (Horizon Discovery) was purchased targeting the 20 selected human PDZ-containing proteins. 